\title{
ANALISIS MANUAL MATERIAL HANDLING DALAM MENGANGKAT BAHAN BAKU DENGAN MENGGUNAKAN METODE PENDEKATAN BIOMEKANIKA KERJA (ERGONOMI) DI PT. XYZ
}

\author{
Ade Andika Saputra ${ }^{1)}$, Wahyudin Wahyudin ${ }^{2)}$, Billy Nugraha ${ }^{3)}$ \\ ${ }^{123}$ Fakultas Teknik, Universitas Singaperbangsa Karawang \\ email: adeandika0405@gmail.com
}

\begin{abstract}
Abstrak
Abstrak: Permasalahan yang sedang terjadi mengenai manual material handling, sebagai berikut: penanganan, pemindahan, pengepakan, penyimpanan dan pengawasan terhadap suatu objek. Hal ini dapat memengaruhi proses produksi perusahaan. Tujuan dari penelitian ini untuk melakukan pemberian usulan sistem kerja saat aktivitas manual material handling. Berupa pengangkatan dan pemindahan thiner di departement warehouse PT. XYZ. Metode dalam penelitian ini biomekanika kerja dengan menggunakan formulasi NIOSH untuk mengetahui nilai RWL serta Li. Selain itu dapat dijadikan sebagai indikator aktivitas yang memiliki resiko. Hal ini dilanjutkan dengan penambahan alat bantu seperti hand pallet dan melakukan analisis pada kondisi fisik pekerja. Hal tersebut berdasarkan konsumsi energi saat aktivitas manual material handling. Hasil evaluasi dapat diketahui bahwa nilai lifting index masing-masing pekerja adalah: Responden $1(0,913)$, Responden $2(0,958)$, Responden $3(0,913)$, Responden $4(0,913)$ dan Responden 5 (0,958). Masing-masing mengalami penurunan jika dibandingkan nilai lifting index sebelumnya. Kemudian nilai yang dikeluarkan setelah adanya perbaikan mengalami penurunan. Sehingga nilai KE adalah: Responden 1 (0,182511 kkal), Responden 2 (0,808563 kkal), Responden 3 (0,642091 kkal), Responden 4 (0,855948 kkal) dan Responden $5(0,931425 \mathrm{kkal})$.
\end{abstract}

Kata kunci: Biomekanika, NIOSH, RWL, Lifting index

Abstract: Current problems regarding manual material handling are as follows: handling, moving, packing, storing and controlling on object. This can affect the company's production process. The purpose of this study is to provide a work system suggestion during manual material handling activities. In the form of appointment and transfer of thiners in the warehouse department of PT. XYZ. The method in this research is work biomechanics using the NIOSH formulation to determine the $R W L$ and Li values. Besides that, it can be used as an indicator of activities that have risks. This is followed by the addition of tools such as hand pallets and analyzing the physical condition of the workers. This is based on energy consumption during manual material handling activities. The results of the evaluation show that the lifting index value for each worker is: Respondent 1 (0.913), Respondent 2 (0.958), Respondent 3 (0.913), Respondent 4 (0.913) and Respondent 5 (0.958). Each of them has decreased when compared to the value of the previous lifting index. Then the value issued after the improvement has decreased. So the value of KE is: Respondent 1 (0.182511 kcal), Respondent $2(0.808563 \mathrm{kcal})$, Respondent $3(0.642091 \mathrm{kcal})$, Respondent $4(0.855948 \mathrm{kcal})$ and Respondent 5 (0.931425 kcal).

Keywords: Biomechanics, NIOSH, RWL, Lifting index

\section{PENDAHULUAN}

PT. XYZ merupakan perusahaan yang bergerak dibidang produksi interior yang berkualitas untuk perumahan, instansi lembaga pemerintahan dan perusahaan.
PT. XYZ terdiri dari beberapa departemen yang saling terintegrasi dan secara terpadu berusaha untuk mewujudkan tujuan perusahaan. Dalam menjalankan rantai produksinya, PT. XYZ membuat perencanaan dan pengendalian barang 
logistik pada bagian warehouse dengan baik dan benar. Sehingga pergerakkan barang dan waktu penyimpanan dapat efektif dan efisien. Namun sangat disayangkan ketika manajemen warehouse sudah baik namun belum ditunjang oleh fasilitas material handling yang dapat memadai. Banyak pekerja disana yang mengeluh akan kesehatannya. Hal ini dikarenakan banyaknya aktivitas pengangkatan dan pemindahan barang secara manual, contoh: Thiner $(20 \mathrm{~kg} / \mathrm{lt})$.

Menurut American Material Handling Society bahwa material handling dinyatakan sebagai seni dan ilmu yang meliputi penanganan (handling), pemindahan (moving), pengepakkan (packaging), penyimpanan (storing) dan pengawasan (controlling) dari material dengan segala bentuknya (Corllet, 1987).

Biomekanika adalah disiplin ilmu yang mengintegrasikan faktor-faktor yang memengaruhi gerakan mansia. Hal ini diambil dari pengetahuan dasar seperti: fisika, matematika, kimia, fisiologi, anatomi dan konsep rekayasa untuk menganalisis gaya yang terjadi pada tubuh (Nurmianto, 2004). Biomekanika merupakan ilmu yang membahas aspekaspek mekanika gerakan-gerakan tubuh manusia (Waters, 1996). Biomekanika adalah kombinasi antara keilmuan mekanika, antropometri dan dasar ilmu kedokteran (biologi dan fisiologi). Dalam dunia kerja yang menjadi perhatian adalah kekuatan kerja otot yang tergantung pada posisi anggota tubuh yang bekerja. Arah gerakan kerja dan perbedaan kekuatan antar bagian tubuh. Selain itu juga kecepatan dan ketelitian serta daya tahan jaringan tubuh terhadap beban (Wignjono, 1996).

Dari beberapa pengertian di atas maka dapat disimpulkan, bahwa biomekanika mencoba memberikan pemahaman atau gambaran terhadap aktivitas yang dilakukan oleh pekerja. Hal ini digunakan untuk memberikan solusi guna meminimumkan gaya dan momen yang diberikan pada pekerja, agar tidak terjadi kecelakaan kerja (Chaffin, 1973).

Penelitian yang dilakukan oleh Imelia Rizki Lestari, Rino Andias Nugraha dan Muhammad Iqbal: Perumusan rekomendasi disusun berdasarkan pengolahan data, analisis data, dan diskusi dengan pihak perusahaan yang bertujuan untuk memaksimalkan proses oksidasi enzimatis. Rekomendasi yang diberikan adalah desain perancangan material handling equipment dengan jenis industrial truck khususnya four-wheel handk truck yang disesuaikan dengan ketentuan dalam proses oksidasi enzimatis (Lestari, Nugraha, \& Iqbal, 2016).

Penelitian yang dilakukan oleh Mochamad Nuri Affa dan Boy Isma Putra: Dari proses manual material handling yang menimbulkan gejalan musculoskeletaldisorder harus dilakukan penyelesaian secara teknis untuk meminimalkan dampak yang timbul tidak ada pekerja (Affa \& Putra, 2017).

Penelitian yang dilakukan oleh Merry Siska dan Septi Ayu Angrayni: Berdasarkan hasil pengolahan dan analisis data terhadap 10 postur tubuh operator didapatkan hasil sebagai berikut: Postur tubuh pertama, ke tiga, ke lima, ke enam, ke tujuh, dan ke sembilan dengan skor akhirnya yaitu 4 dan nilai action level 2, artinya yaitu kondisi ini berbahaya sehingga pemeriksaan dan perubahan diperlukan dengan segera saat itu juga. Postur tubuh ke dua, ke delapan, dan ke sepuluh dengan skor akhir 4 dan action level 2, artinya yaitu aktivitas ini memerlukan pemeriksaan lanjutan dan juga memerlukan perubahan-perubahan terhadap postur tubuh tersebut. Postur tubuh ke empat dengan skor akhir 2 dan action level 1, artinya postur ini bisa diterima jika tidak dipertahankan atau tidak berulang dalam periode yang lama (Siska \& Angrayni, 2018).

Penelitian yang dilakukan oleh Eli Mas'idah, Wiwiek Fatmawati dan Lazib Ajibta: pada hasil penelitian nilai lifting index (LI) dengan massa beban $75 \mathrm{~kg}$ pada 
kondisi awal nilai LI rata-rata adalah 5,52, nilai tersebut sangat ekstrim dan sangat beresiko menyebabkan cedera tulang belakang. Setelah dilakukan perbaikan sistem kerja pada nilai LI rata-rata diperoleh 2,8, nilai LI setelah perbaikan masih dalam batas toleransi. Nilai konsumsi energi kondisi awal rata-rata adalah 2,31. Hal ini menunjukkan konsumsi energi oleh para pekerja termasuk kategori beban kerja yang sangat berat. Setelah perbaikan sistem kerja konsumsi energi oleh pekerja angkat tersebut menjadi menurun yaitu 1,16 , hal ini menunjukkan pekerjaan tersebut dalam kategori beban kerja sedang dan pekerja tersebut tidak cepat mengalami kelelahan (Mas'idah, Fatmawati, \& Ajibta, 2009).

Penelitian yang dilakukan oleh Dede Muslim dan Anita Ilmaniati: hasil penelitian ini menunjukan bahwa jarak lintasan material pada lantai produksi dengan layout yang baru berubah menjadi 71,7 meter, dengan ongkos material handling/meter berkurang dari Rp.1,105,954 menjadi Rp.712,402 atau berkurang sebesar 35\% (Muslim \& Ilmaniati, 2018).

Penelitian yang dilakukan oleh Muhammad Baried Yuliar, Hendro Prassetiyo dan Rispianda: aspek-aspek yang diperhatikan dalam perancangan ini adalah aspek kekuatan material. Agar dapat menahan beban yang diangkat dan perbaikan postur tubuh agar beban tubuh yang diterima operator menjadi berkurang (Yuliar, Prassetiyo, \& Rispianda, 2013).

Penelitian yang dilakukan oleh Muhammad Nur dan Ario Dariatma: setelah dilakukan perancangan ulang troli dorong diperoleh indeks beban postur pekerja kegiatan mengangkat sebesar 4, membawa sebesar 5 dan meletakkan sebesar 4. Postur dengan lebih dari 10 menit dan indeks beban postur 5 atau kurang. Kategori postur ini dapat diterima dan tidak ada tindakkan perbaikan yang dibutuhkan (Nur \& Dariatma, 2019).

Penelitian yang dilakukan oleh Bintari, Evi Nopiyanti dan Agus Joko Susanto: hasil penelitian, diketahui bahwa tingkat risiko dari 4 jenis pekerjaan erection pumping, 2 pekerjaan termasuk kategori risiko sedang skor (3-4) dan 2 pekerjaan lainnya termasuk kategori tinggi skor (56). Oleh karena itu, untuk mengurangi risiko ergonomi pada pekerja, sebaiknya melakukan perbaikan desain tempat kerja dan melakukan peregangan otot sebelum dan sesudah bekerja (Bintari, Nopiyanti, \& Susanto, 2017).

Penelitian yang dilakukan oleh Amanda Nur Cahyawati: dari hasil pengamatan didapatkan nilai lifting index sebesar 2,029 untuk origin dan 1,530 untuk destination dimana nilai lifting index $>1$. Sehingga dapat disimpulkan bahwa pekerjaan tersebut dapat menyebabkan risiko cidera. Karena berat beban melebihi batas pengangkatan (Cahyawati, 2018).

Penelitian yang dilakukan oleh Ahmad Mushthofa As'Adi, Anita Dewi Prahastuti Sujoso dan Irma Prasetyowati: hasil analisis data menunjukkan ada hubungan antara umur $(\mathrm{p}=0,00001)$, dan status gizi (IMT) $(\mathrm{p}=0,041)$, dengan keluhan muskuloskeletal akibat kerja. Sedangkan kebiasaan merokok $(\mathrm{p}=0,249$ dan masa kerja $(\mathrm{p}=0,170)$ menunjukkan tidak ada hubungan dengan keluhan muskuloskeletal karena pekerjaan, dan untuk bahan panduan penanganan $(\mathrm{MMH})(\mathrm{p}=0,018)$ dengan menggunakan metode RWL dan $\mathrm{Li}$ pengukuran ditunjukkan ada hubungan antara manual material handling dengan keluhan muskuloskeletal akibat kerja (As'Adi, Sujoso, \& Prasetyowati, 2014).

Tujuan dari penelitian ini untuk melakukan pemberian usulan sistem kerja saat aktivitas manual material handling. Berupa pengangkatan dan pemindahan thiner di departement warehouse PT. XYZ. Berdasarkan penelitian yang dilakukan terdapat bahwa limit pengangkatan beban yang dapat diproses oleh pekerja. Khususnya dalam melakukan kegiatan manual material handling yang kemudian akan dilakukan pengujian lebih lanjut menggunakan lifting index (Li). Jika 
terdapat pekerja yang menyatakan bahwa nilai $\mathrm{Li}<1$ maka pekerjaan tersebut dikatakan aman. Jika didapatkan nilai Li > 1 maka pekerjaan tersebut membahayakan dan beresiko mengalami cidera tulang belakang (musculoskeletal disorder). Maka permasalahan yang sedang terjadi mengenai manual material handling, sebagai berikut: penanganan, pemindahan, pengepakan, penyimpanan dan pengawasan terhadap suatu objek. Hal ini dapat memengaruhi proses produksi perusahaan.

\section{METODE PENELITIAN}

Pengamatan dilakukan pada pekerja di PT. XYZ pada bagian departement warehousing, yang melakukan pengangkatan dan pemindahan thiner dengan berat beban $20 \mathrm{~kg} /$ drum. Alat yang digunakan untuk pengujian denyut nadi masih menggunakan teknik manual, yaitu dengan menekan bagian nadi di pergelanggan tangan. Selain itu ditunjang dengan stopwatch dan alat ukur meteran.

Penelitian ini dilaksanakan untuk mengetahui beban maksimal yang diangkat oleh pekerja di bagian departement warehousing. Momen gaya, konsumsi energi dan denyut nadi yang digunakan sebagai penentuan batas maksimal yang dapat diangkat oleh pekerja. Berikut beberapa dokumentasi pekerja yang melakukan pengangkatan dan pemindahan secara manual. Seperti pada Gambar 1., Gambar 2. dan Gambar 3. di bawah ini:

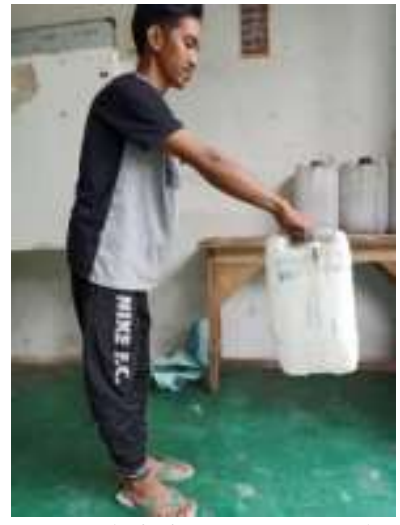

Gambar 1. Aktivitas Pengangkatan (1)

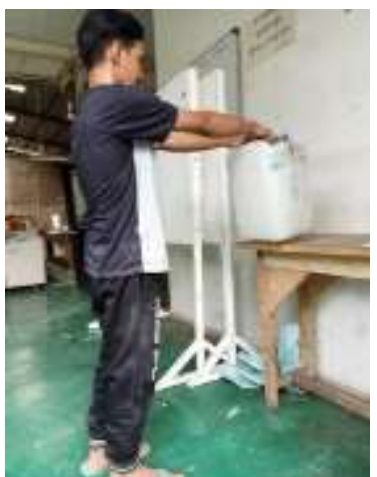

Gambar 2. Aktivitas Pengangkatan (2)

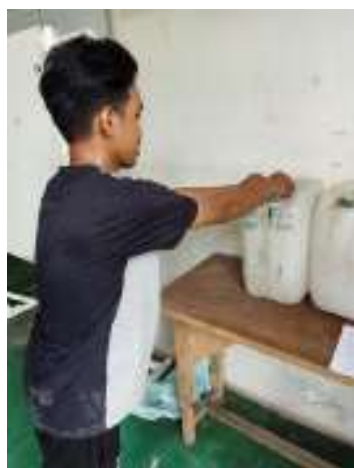

Gambar 3. Aktivitas Pengangkatan (3)

Kerangka pemecahan masalah pada penelitian ini dalam bentuk flowchart. Dengan tujuan agar telihatnya aktivitas atau tahapan penelitian yang dilakukan dalam penelitian ini Seperti pada Gambar 4. di bawah ini: 


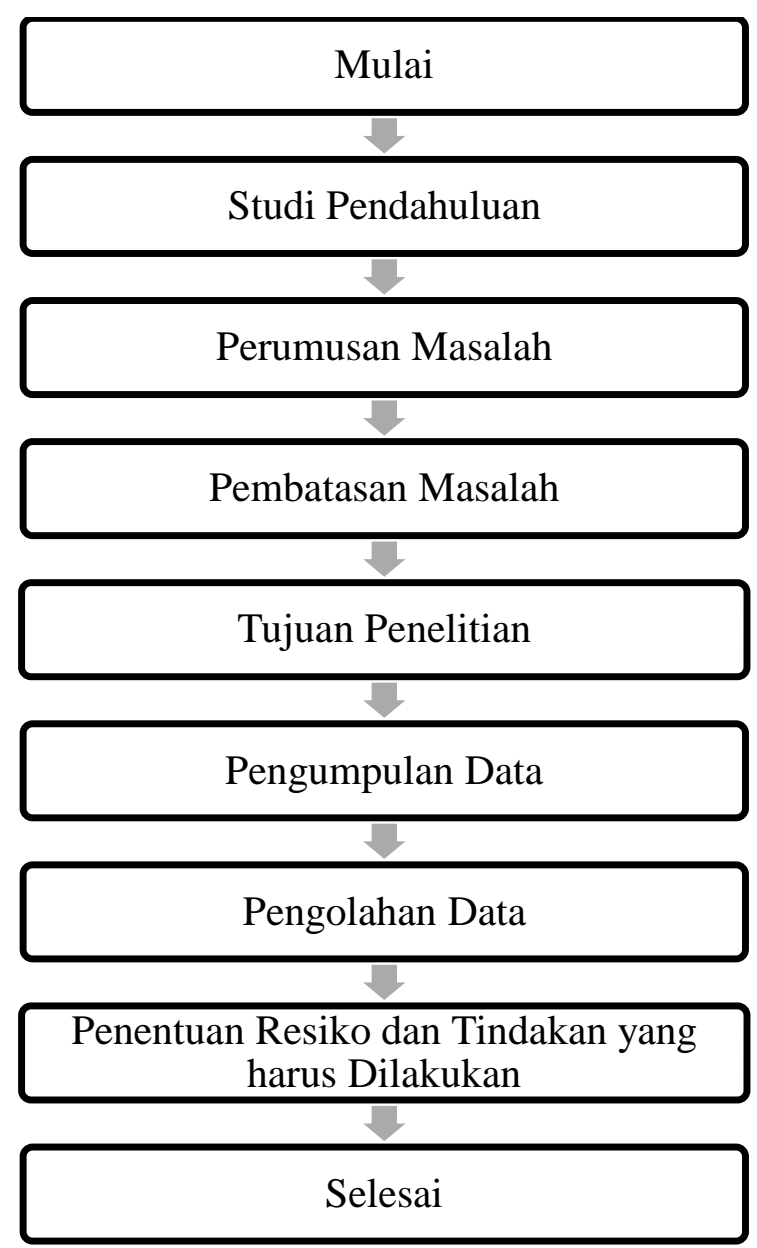

Gambar 4. Kerangka Pemacahan Masalah

\section{HASIL DAN PEMBAHASAN}

Berikut ini data pengamatan yang didapatkan oleh pekerja di PT. XYZ pada bagian departement warehousing, dengan kegiatan pengangkatan dan pemindahan thiner:

1. Data ciri-ciri fisik pada pekerja, berikut pada Tabel 1. di bawah ini:

Tabel 1. Data Ciri-Ciri Fisik pada Pekerja

\begin{tabular}{cccc}
\hline Nama & Usia & Tinggi & Berat \\
\hline Responden 1 & 31 & $165 \mathrm{~cm}$ & $48 \mathrm{~kg}$ \\
Responden 2 & 32 & $170 \mathrm{~cm}$ & $73 \mathrm{~kg}$ \\
Responden 3 & 34 & $168 \mathrm{~cm}$ & $54 \mathrm{~kg}$ \\
Responden 4 & 25 & $167 \mathrm{~cm}$ & $85 \mathrm{~kg}$ \\
Responden 5 & 40 & $155 \mathrm{~cm}$ & $57 \mathrm{~kg}$ \\
\hline
\end{tabular}

2. Data pengamatan proses pengangkatan thiner yang dilakukan oleh pekerja, berikut pada Tabel 2. di bawah ini:
Tabel 2. Data Ciri-Ciri Fisik pada Pekerja

\begin{tabular}{ccccccc}
\hline Nama & H & V & D & A & Fm & Cm \\
\hline Responden 1 & 60 & 40 & 60 & 45 & 0,9 & 1 \\
Responden 2 & 50 & 40 & 60 & 45 & 0,9 & 1 \\
Responden 3 & 50 & 40 & 60 & 45 & 0,9 & 1 \\
Responden 4 & 40 & 40 & 60 & 45 & 0,9 & 1 \\
Responden 5 & 60 & 40 & 60 & 45 & 0,9 & 1 \\
\hline
\end{tabular}

\section{Keterangan:}

$\mathrm{H}$ : Jarak horisontal, dihitung dari beban sampai tulang lengan yag berlawanan arah dengan posisi badan.

V : Jarak vertikal, dihitung dari dasar lantai sampai dengan permukaan atas bak truk yang bersentuhan langsung dengan beban.

D : Jarak $A_{o}-A_{1}$, Dihitung dari permukaan atas meja sampai dengan penurunan beban.

A : Sudut assimetrik, sudut tubuh pada saat pengangkatan beban.

Fm : Frekuensi 4 pengangkatan/menit, dari tabel pengalu frekuensi.

$\mathrm{Cm}$ : Tabel coupling multiplier $\mathrm{V}>75 \mathrm{~cm}$ kategori poor.

3. Data denyut nadi setiap pekerja, berikut pada Tabel 3. di bawah ini:

Tabel 3. Data Denyut Nadi setiap Pekerja

\begin{tabular}{ccc}
\hline Nama & $\begin{array}{c}\text { Denyut Nadi } \\
\text { Awal } \\
\text { (pulse/menit) }\end{array}$ & $\begin{array}{c}\text { Denyut Nadi } \\
\text { Akhir } \\
\text { (pulse/menit) }\end{array}$ \\
\hline Responden 1 & 110 & 130 \\
Responden 2 & 115 & 135 \\
Responden 3 & 105 & 136 \\
Responden 4 & 110 & 132 \\
Responden 5 & 117 & 138 \\
\hline
\end{tabular}

4. Data pengamatan momen gaya pekerja, berikut pada Tabel 4. di bawah ini:

Tabel 4. Data Ciri-Ciri Fisik pada Pekerja

\begin{tabular}{llllllll}
\hline \multicolumn{1}{c}{ Nama } & D & w & h & b & E & W & OH \\
& & & & & & & \\
\hline Responden 1 & 9 & 480 & 8 & 4 & 5 & 200 & 45 \\
Responden 2 & 9 & 730 & 8 & 4 & 5 & 200 & 45 \\
Responden 3 & 9 & 540 & 8 & 4 & 5 & 200 & 45 \\
Responden 4 & 9 & 850 & 8 & 4 & 5 & 200 & 45 \\
Responden 5 & 9 & 570 & 8 & 4 & 5 & 200 & 45 \\
\hline Keterangan: \\
D : Jarak dari gaya perut. \\
w : Berat badan x gravitasi. \\
h : Jarak sumbu pusat ke massa beban. \\
b : L5/S1 ke pusat massa beban. \\
E : Jarak otot spical erector ke L5/S1. \\
W : Berat beban x gravitasi. \\
OH : Sudut tubuh pengangkatan beban.
\end{tabular}

5. Data perhitungan hasil recommend weight limit (RWL) sebelum dan sesudah perbaikan, berikut pada Tabel 5. dan 6. di bawah ini: 
Tabel 5. Hasil Recommend Weight Limit (RWL) Sebelum Perbaikan

\begin{tabular}{ccccccccccccccc}
\hline Nama & H & V & D & A & Fm & Cm & HM & VM & AM & DM & FM & CM & LC & RWL \\
\hline Responden 1 & 60 & 40 & 60 & 45 & 0,9 & 1 & 0,4 & 1,07 & 0,85 & 0,89 & 0,9 & 1 & 23 & 7,103369 \\
Responden 2 & 50 & 40 & 60 & 45 & 0,9 & 1 & 0,5 & 1,07 & 0,85 & 0,89 & 0,9 & 1 & 23 & 8,524043 \\
Responden 3 & 50 & 40 & 60 & 45 & 0,9 & 1 & 0,5 & 1,07 & 0,85 & 0,89 & 0,9 & 1 & 23 & 8,524043 \\
Responden 4 & 40 & 40 & 60 & 45 & 0,9 & 1 & 0,6 & 1,07 & 0,85 & 0,89 & 0,9 & 1 & 23 & 10,65505 \\
Responden 5 & 60 & 40 & 60 & 45 & 0,9 & 1 & 0,4 & 1,07 & 0,85 & 0,89 & 0,9 & 1 & 23 & 7,103369 \\
\hline
\end{tabular}

Dari perhitungan tersebut didapat sebesar: Responden 1 (7,103 kg), bahwa pekerjaan pemindahan dan Responden $2(8,524 \mathrm{~kg})$, Responden 3 pengangkatan thiner yang dilakukan $\quad(8,524 \mathrm{~kg})$, Responden $4(10,655 \mathrm{~kg})$ oleh pekerja PT. XYZ memiliki dan Responden $5(7,103 \mathrm{~kg})$.

rekomendasi batas pengangkatan beban

Tabel 6. Hasil Recommend Weight Limit (RWL) Sesudah Perbaikan

\begin{tabular}{ccccccccccccccc}
\hline Nama & H & V & D & A & Fm & Cm & HM & VM & AM & DM & FM & CM & LC & RWL \\
\hline Responden 1 & 20 & 40 & 60 & 45 & 0,9 & 1 & 1,25 & 1,10 & 0,85 & 0,89 & 0,9 & 1 & 23 & 21,90481 \\
Responden 2 & 21 & 40 & 60 & 45 & 0,9 & 1 & 1,19 & 1,10 & 0,85 & 0,89 & 0,9 & 1 & 23 & 20,86172 \\
Responden 3 & 20 & 40 & 60 & 45 & 0,9 & 1 & 1,25 & 1,10 & 0,85 & 0,89 & 0,9 & 1 & 23 & 21,90481 \\
Responden 4 & 20 & 40 & 60 & 45 & 0,9 & 1 & 1,25 & 1,10 & 0,85 & 0,89 & 0,9 & 1 & 23 & 21,90481 \\
Responden 5 & 21 & 40 & 60 & 45 & 0,9 & 1 & 1,19 & 1,01 & 0,85 & 0,89 & 0,9 & 1 & 23 & 20,86172 \\
\hline
\end{tabular}

Dari perhitungan tersebut didapat bahwa pekerjaan pemindahan dan pengangkatan thiner yang dilakukan oleh pekerja PT. XYZ dengan menggunakan alat bantu seperti kereta tarik, memiliki rekomendasi batas pengangkatan beban sebesar: Responden 1 (21,904 kg), Responden 2 $(20,861 \mathrm{~kg})$, Responden 3 (21.904 kg), Responden 4 (21,904 kg) dan Responden 5 (20,861).

6. Data hasil perhitungan lifting index (Li) sebelum dan sesudah perbaikan, berikut pada Tabel 7. dan 8. di bawah ini:

Tabel 7. Hasil Lifting Index (Li) Sebelum Perbaikan

\begin{tabular}{cccc}
\hline Nama & W & RWL & Li \\
\hline Responden 1 & 20 & 7,10336 & 2,81556 \\
Responden 2 & 20 & 8,52404 & 2,34630 \\
Responden 3 & 20 & 8,52404 & 2,34630 \\
Responden 4 & 20 & 10,65505 & 1,87704 \\
Responden 5 & 20 & 7,10336 & 2,81556 \\
\hline
\end{tabular}

Dari hasil perhitungan lifting index (Li) yang didapat dari perhitungan biomekanika. Didapatkan bahwa nilai $\mathrm{Li}>1$, maka aktivitas tersebut mengandung resiko cidera tulang belakang. Sehingga perlu dilakukan perbaikan dengan menggunakan alat bantu manual atau perbaikan tata letak gudang agar lebih efektif dan efisien.
Tabel 8. Hasil Lifting Index (Li) Sesudah Perbaikan

\begin{tabular}{cccc}
\hline Nama & W & RWL & Li \\
\hline Responden 1 & 20 & 21,90481 & 0,913042 \\
Responden 2 & 20 & 20,86172 & 0,958694 \\
Responden 3 & 20 & 21,90481 & 0,913042 \\
Responden 4 & 20 & 21,90481 & 0,913042 \\
Responden 5 & 20 & 20,86172 & 0,958694 \\
\hline
\end{tabular}

Dari hasil perhitungan lifting index (Li) yang didapat dari perhitungan biomekanika. Didapatkan bahwa nilai Li < 1, maka aktivitas tersebut maka aktivitas tersebut aman untuk dilakukan secara berulang-ulang. Hal ini dapat terjadi karena dilakukannya perbaikan dengan menambahkan alat bantu kereta tarik untuk pemindahan dan pengangkatan.

7. Data hasil perhitungan KE, Ei dan Et sebelum perbaikan pada Tabel 9., saat kerja sebelum perbaikan pada Tabel 10., sesudah perbaikan pada Tabel 11., saat kerja sesudah perbaikan pada Tabel 12., konsumsi energi sebelum perbaikan pada Tabel 13. dan konsumsi energi sesudah perbaikan pada Tabel 14. di bawah ini: 
Tabel 9. Hasil Pengeluaran Energi Sebelum Kerja (Ei) Sebelum Perbaikan

\begin{tabular}{ccc}
\hline \multirow{2}{*}{ Nama } & $\begin{array}{c}\text { Denyut Nadi Awal } \\
(\text { DNI) }\end{array}$ & Eulse/menit $)$ \\
\hline Responden 1 & 110 & 4,99266 \\
Responden 2 & 115 & 5,40884 \\
Responden 3 & 105 & 4,60006 \\
Responden 4 & 110 & 4,99266 \\
Responden 5 & 117 & 5,58191 \\
\hline
\end{tabular}

Berdasarkan hasil perhitungan konsumsi energi pada pekerja PT. XYZ sebelum melakukan pekerjaan didapat bahwa Responden 1 (4,992 kkal), Responden 2 (5,408 kkal), Responden 3 (4,600 kkal), Responden 4 (4,992 kkal) dan Responden $(5,581 \mathrm{kkal})$.

Tabel 10. Hasil Pengeluaran Energi Saat Kerja (Et) Sebelum Perbaikan

\begin{tabular}{ccc}
\hline Nama & $\begin{array}{c}\text { Denyut Nadi Awal } \\
\text { (DNI) }(\text { pulse/menit })\end{array}$ & Ei \\
\hline Responden 1 & 130 & 6,79890 \\
Responden 2 & 135 & 7,30943 \\
Responden 3 & 136 & 7,41436 \\
Responden 4 & 132 & 7,00028 \\
Responden 5 & 138 & 7,62706 \\
\hline
\end{tabular}

Berdasarkan hasil perhitungan konsumsi energi pada pekerja PT. XYZ saat melakukan pekerjaan didapat bahwa Responden 1 (6,798 kkal), Responden 2 (7,309 kkal), Responden 3 (7,414 kkal), Responden 4 (7,000 kkal) dan Responden (7,627 kkal).
Tabel 11. Hasil Pengeluaran Energi Sebelum Kerja (Ei) Setelah Perbaikan

\begin{tabular}{ccc}
\hline Nama & $\begin{array}{c}\text { Denyut Nadi Awal } \\
\text { (DNI) }\end{array}$ & Eulse/menit) \\
\hline Responden 1 & 110 & 5,84860 \\
Responden 2 & 115 & 5,40884 \\
Responden 3 & 118 & 5,66987 \\
Responden 4 & 110 & 4,99266 \\
Responden 5 & 118 & 5,66987 \\
\hline
\end{tabular}

Berdasarkan hasil perhitungan konsumsi energi pada pekerja PT. XYZ sebelum melakukan pekerjaan didapat bahwa Responden 1 (5,848 kkal), Responden 2 (5,408 kkal), Responden 3 (5,669 kkal), Responden 4 (4,992 kkal) dan Responden $(5,659 \mathrm{kkal})$.

Tabel 12. Hasil Pengeluaran Energi Saat Kerja (Et) Setelah Perbaikan

\begin{tabular}{ccc}
\hline Nama & $\begin{array}{c}\text { Denyut Nadi Awal } \\
\text { (DNI) }(\text { pulse/menit })\end{array}$ & $\mathrm{Ei}$ \\
\hline Responden 1 & 122 & 6,03112 \\
Responden 2 & 124 & 6,21740 \\
Responden 3 & 125 & 6,31196 \\
Responden 4 & 120 & 5,84860 \\
Responden 5 & 128 & 6,60129 \\
\hline
\end{tabular}

Berdasarkan hasil perhitungan konsumsi energi pada pekerja PT. XYZ saat melakukan pekerjaan didapat bahwa Responden 1 (6,031 kkal), Responden 2 (6,217 kkal), Responden 3 (6,311 kkal), Responden 4 (5,848 kkal) dan Responden $(6,601$

kkal).

Tabel 13. Hasil Nilai Konsumsi Energi (KE) Sebelum Perbaikan

\begin{tabular}{ccccccc}
\hline Nama & $\begin{array}{c}\text { Denyut Nadi Awal } \\
\text { (DNI) }(\text { pulse/menit })\end{array}$ & $\begin{array}{c}\text { Denyut Nadi Awal } \\
(\text { DNK) }(\text { pulse/menit })\end{array}$ & $\begin{array}{c}\text { Berat Badan } \\
(\mathrm{Kg})\end{array}$ & Ei & Et & KE \\
\hline Responden 1 & 110 & 130 & 48 & 4,99266 & 6,79890 & 1,80624 \\
Responden 2 & 115 & 135 & 73 & 5,40884 & 7,30943 & 1,90058 \\
Responden 3 & 105 & 136 & 54 & 4,60006 & 7,41436 & 2,81429 \\
Responden 4 & 110 & 132 & 85 & 4,99266 & 7,00028 & 2,00762 \\
Responden 5 & 117 & 138 & 57 & 5,58191 & 7,62706 & 2,04515 \\
\hline
\end{tabular}

Berdasarkan hasil perhitungan, (2,007 kkal) dan Responden $5(2,045$
diketahui bahwa pekerja yang melakukan pemindahan dan pengangkatan thiner mengeluarkan energi sebesar berikut: Responden 1 (1,806 kkal), Responden 2 (1,900 kkal), Responden 3 (2,814 kkal), Responden 4 kkal). Hasil tersebut jika mengacu pada kriteria pekerjaan termasuk dalam pekerjaan yang light-moderate work. Dikarenakan terdapat pekerjaan yang membutuhkan konsumsi $<2,5 \mathrm{kkal}$, dan $>2,5 \mathrm{kkal}$. 
Tabel 14. Hasil Nilai Konsumsi Energi (KE) Sesudah Perbaikan

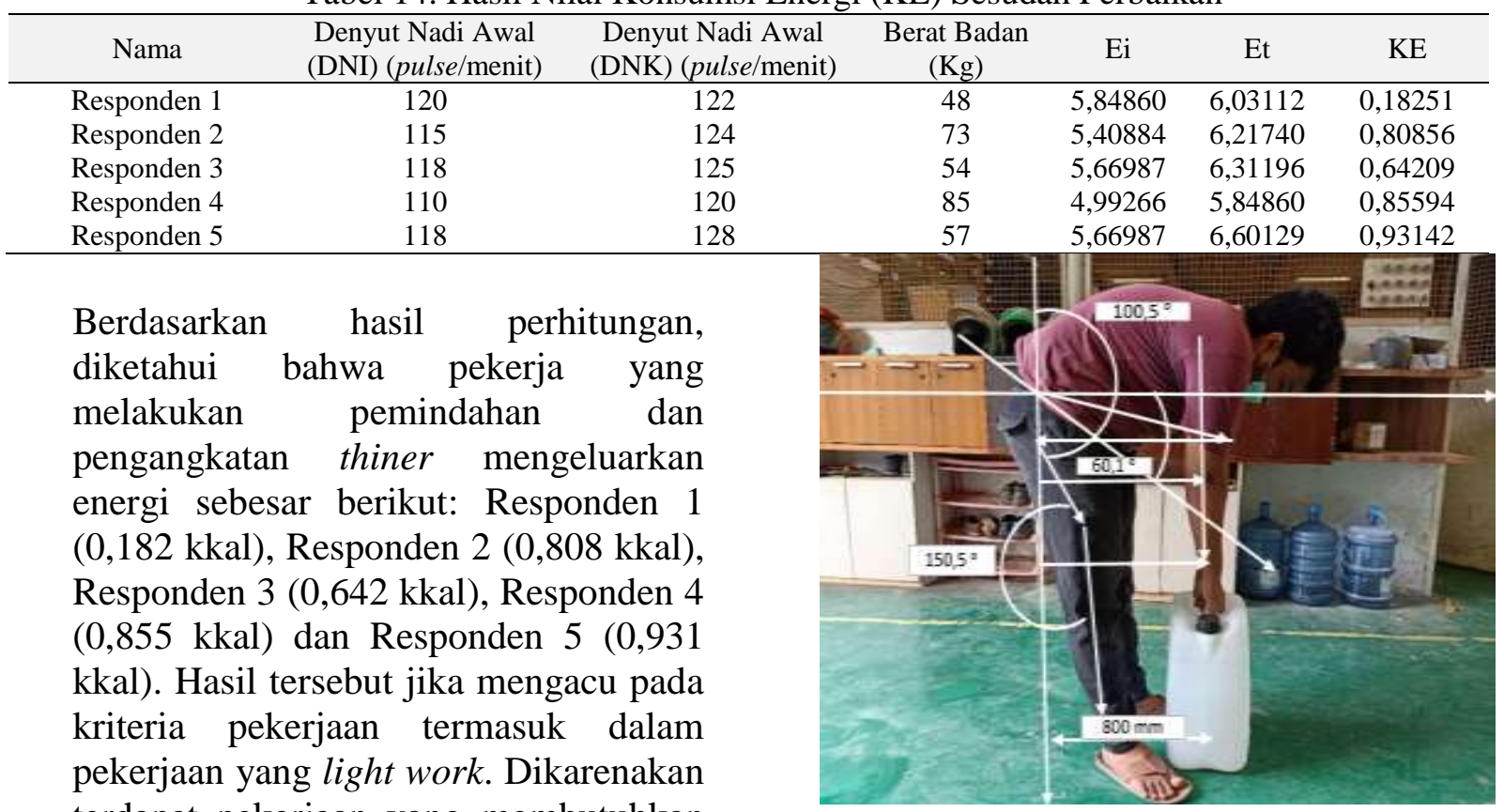
terdapat pekerjaan yang membutuhkan konsumsi $<2,5 \mathrm{kkal}$.

Gambar 5. Ilustrasi Perhitungan Momen Gaya

8. Data hasil perhitungan momen gaya, terilustrasi pada Gambar 5. di bawah ini:

9. Berikut hasil perhitungan momen gaya sebelum dan sesudah perbaikan, pada Tabel 15. dan 16. di bawah ini:

Tabel 15. Hasil Nilai Momen Gaya Sebelum Perbaikan

\begin{tabular}{cccccccccccc}
\hline Nama & D & w & h & B & E & W & ML5/S1 & PA & AA & FA & Momen Gaya \\
\hline Responden 1 & 9 & 480 & 8 & 10 & 5 & 200 & 680 & 0,56876 & 465 & 264,4762 & 5924 \\
Responden 2 & 9 & 730 & 8 & 10 & 5 & 200 & 930 & 0,99927 & 465 & 464,6649 & 8064 \\
Responden 3 & 9 & 540 & 8 & 10 & 5 & 200 & 740 & 0,66226 & 465 & 307,9553 & 6446 \\
Responden 4 & 9 & 850 & 8 & 10 & 5 & 200 & 1050 & 1,24325 & 465 & 578,1111 & 9059 \\
Responden 5 & 9 & 570 & 8 & 10 & 5 & 200 & 770 & 0,71137 & 465 & 330,7912 & 6705 \\
\hline
\end{tabular}

Berdasarkan perhitungan momen gaya pada kondisi awal masing-masing pekerja sebagai berikut: Responden 1 $(5924 \mathrm{~N})$, Responden 2 (8054 N), Responden 3 (6446 N), Responden 4 $(9059 \mathrm{~N})$ dan Responden 5 (6705 N).

Berdasarkan data di atas dapat disimpulkan bahwa masih terdapat beberapa pekerja yang menghasilkan momen gaya melebihi batas rekomendasi NIOSH, yaitu 6500 Newton.

Tabel 16. Hasil Nilai Momen Gaya Sesudah Perbaikan

\begin{tabular}{cccccccccccc}
\hline Nama & D & w & h & B & E & W & ML5/S1 & PA & AA & FA & Momen Gaya \\
\hline Responden 1 & 9 & 480 & 10 & 4 & 5 & 200 & 680 & 0,56876 & 465 & 264,4762 & 3444 \\
Responden 2 & 9 & 730 & 10 & 4 & 5 & 200 & 930 & 0,99927 & 465 & 464,6649 & 4084 \\
Responden 3 & 9 & 540 & 10 & 4 & 5 & 200 & 740 & 0,66226 & 465 & 307,9553 & 3606 \\
Responden 4 & 9 & 850 & 10 & 4 & 5 & 200 & 1050 & 1,24325 & 465 & 578,1111 & 4359 \\
Responden 5 & 9 & 570 & 10 & 4 & 5 & 200 & 770 & 0,71137 & 465 & 330,7912 & 3685 \\
\hline
\end{tabular}

Berdasarkan perhitungan momen gaya setelah dilakukan perbaikan sistem, dengan menambahkan alat bantu seperti kereta tarik pada kondisi tersebut. Didapatkan nilai momen gaya pada masing-masing pekerja sebagai berikut:
Responden 1 (3444 N), Responden 2 $(4048 \mathrm{~N})$, Responden 3 (3606 N), Responden $4(4359 \mathrm{~N})$ dan Responden $5(3685 \mathrm{~N})$. Berdasarkan data di atas dapat disimpulkan bahwa pekerjaan dikatakan aman. Sehingga dapat 
meminimumkan cidera tulang belakang (musculoskeletal disorder), karena berada di bawah batas rekomendasi NIOSH yaitu 6500 Newton.

\section{KESIMPULAN}

Berdasarkan nilai lifting index (Li) dengan massa beban $20 \mathrm{~kg}$ pada kondisi awal. Nilai masing-masing lifting index pada pekerja adalah: Responden $1(2,815)$, Responden 2 (2,346), Responden 3 (2,34), Responden $4(1,877)$ dan Responden 6 $(2,815)$. Nilai tersebut menyatakan bahwa pekerjaan pengangkatan berpotensi menimbulkan cidera tulang belakang (muculoskeletal disorder). Sedangkan setelah perbaikan sistem kerja dengan menambahkan alat bantu kereta tarik. Maka nilai lifting index masing-masing pekerja adalah: Responden 1 (0,913), Responden 2 (0,958), Responden 3 $(0,913)$, Responden $4 \quad(0,913)$ dan Responden 5 (0,958). Berdasarkan nilai konsumsi energi yang dikeluarkan setelah adanya perbaikan mengalami penurunan. Sehingga nilai $\mathrm{KE}$ adalah: Responden 1 $(0,182511 \mathrm{kkal})$, Responden 2 (0,808563 kkal), Responden 3 (0,642091 kkal), Responden $4 \quad(0,855948$ kkal $)$ dan Responden 5 (0,931425 kkal). Maka penelitian ini untuk melakukan pemberian rekomendasi sistem kerja yang sesuai ilmu ergonomi. Penerapan dilakukan saat terjadinya aktivitas manual material handling.

Perlu adanya fasilitas penunjang pekerjaan yang lebih baik untuk ,penunjang aktivitas pekerjaan yang dilakukan di bagian departement warehousing PT. XYZ Perlu adanya penataan inventori yang lebih baik agar memudahkan pekerja untuk menjangkau serta menyimpan material di bagian departement warehousing PT. XYZ. Selain itu perlu adanya pemberian pemahaman pengetahuan terkait K3 di PT. XYZ, agar pekerja lebih memahami serta mengetahui dampak dan resiko apa saja yang terjadi ketika melaksanakan suatu pekerjaan.

\section{DAFTAR PUSTAKA}

Affa, M. N., \& Putra, B. I. (2017). Analisis Manual Material Handling pada Pekerja Borongan di PT. JC dengan Metode NBM dan RWL. Journal Productivity, Optimization, and Manufacturing System, 22-32.

As'Adi, A. M., Sujoso, A. D., \& Prasetyowati, I. (2014). Hubungan Antara Karakteristik Individu dan Manual Material Handling dengan Keluhan Muskuloskeletal Akibat Kerja (The Relationship Between Individual Characteristics and Manual Material Handling with Musculosceletal Complaints Due To Work). e-Jurnal Pustaka Kesehatan, 271-276.

Bintari, Nopiyanti, E., \& Susanto, A. J. (2017). Risiko Ergonomi pada Pekerja Erection Pumping dengan Metode Ergonomic Assessment Survey (EASY) di Workshop Gear Reducer PT. X, Cileungsi, Bogor Tahun 2015. Jurnal Bidang Ilmu Kesehatan, 581-590.

Cahyawati, A. N. (2018). Analisis Manuall Material Handling pada Pengangkatan Batu Bata dengan Metode Lifting Index. Seminar Nasional Teknologi dan Rekayasa (SENTRA) 2018 (pp. 125-130). Malang: SENTRA.

Chaffin, D. K. (1973). A Longitudinal with Occupational Lifting Factors. American Industrial Hygiene Association Journal, 34-43.

Corllet, E. R. (1987). Assesment of Workload from Measurement of 
Statue, Applied Ergonomics. New York: Marcel Deker Inc.

Lestari, I. R., Nugraha, R. A., \& Iqbal, M. (2016). Perancangan Material Handling Equipment pada Proses Penggilingan ke Oksida Enzimatis Bubuk Teh Menggunakan Metode Perancangan Produk Rasional pada PT. Perkebunan Nusantara VIII Rancabali. Jurnal Rekayasa Sistem \& Industri, 18-25.

Mas'idah, E., Fatmawati, W., \& Ajibta, L. (2009). Analisa Manual Material Handling (MMH) dengan Menggunakan Metode Biomekanika untuk Mengidentifikasi Resiko Cidera Tulang Belakang (Musculoskeletal Disorder) (Studi Kasus pada Buruh Pengangkat Beras di Pasar Jebor Demak). Jurnal Sultan Agung, 37-56.

Muslim, D., \& Ilmaniati, A. (2018). Usulan Perbaikan Tata Letak Fasilitas terhadap Optimalisasi Jarak dan Ongkos Material Handling dengan Pendekatan Systematic Layout Planning (SLP) di PT. Transplant Indonesia. Jurnal Media Teknik dan Sistem Industri, 45-52.

Nur, M., \& Dariatma, A. (2019). Usulan Perbaikan Postur Kerja Aktivitas Pemuatan Barang Menggunakan Metode Loading On The Upper Body Assessment (LUBA). Industrial Engineering Journal, 110.

Nurmianto, E. (2004). Ergonomi, Konsep Dasar dan Aplikasinya. Surabaya: PT. Guna Widya.

Siska, M., \& Angrayni, S. A. (2018). Analisis Postur Kerja Manual Material Handling pada Aktivtas Pemindahan Pallet Menggunakan Rappid Upper Limb Activity
(RULA) di PT. Alam Permata Riau. Jurnal Sains, Teknologi dan Industri, 77-86.

Sulistyani. (2003). Analisa Manual Material Handling dengan Konsep NIOSH. Surakarta: Fakultas Teknik, Universitas Muhammadiyah Surakarta.

Waters, T. A. (1996). Manual Material Handling. New York: Marcel Deker Inc.

Wignjono, S. (1996). Tata Letak Pabrik dan Pemindahan Bahan. Surabaya: Institut Teknologi Sepuluh November.

Yuliar, M. B., Prassetiyo, H., \& Rispianda. (2013). Usulan Rancangan Handtruck Menggunakan Metode Verein Deutsche Inginieuer 2222 (Studi Kasus di Pasar Induk Caringin Bandung). Jurnal Online Institut Teknologi Nasional, 74-84. 